\title{
Hacia un sistema latinoamericano de seguridad regional
}

La guerra del Atlántico Sur es un motivo de honda preocupación para todos los latinoamericanos. Es muy probable que, más allá de las víctimas y los costos directos de la guerra, América Latina no vuelva a ser la misma después de las Malvinas.

Esto afecta muy especialmente las relaciones externas de nuestros países. Hemos visto cómo un peligro que se había venido señalando desde hacía largo tiempo -el aumento de nuestra vulnerabilidad externa - ha adquirido dimensiones inaceptables, que colocan a nuestra región a merced de decisiones políticas, económicas y estratégicas al servicio de los intereses de las grandes potencias, cuya defensa invariablemente es puesta por encima de todo otro compromiso o alianza.

Hemos visto romperse también todos los marcos en que se desenvolvía la acción internacional de nuestros países: la profunda contraposición de intereses existente entre los dos bloques que participaban en el llamado diálogo Norte-Sur se ha revelado en toda su crudeza; se ha puesto de manifiesto la mistificación en que se basaba el Sistema Interamericano; por otra parte, el surgimiento de un movimiento de solidaridad latinoamericana - no exento de oportunismos y de grietas- no debería infundirnos falsas esperanzas sino más bien servir de estímulo para buscar fórmulas que corrijan errores del pasado y cimenten esa precaria unidad regional sobre bases duraderas.

Al mismo tiempo, durante los últimos años nunca se había puesto en evidencia de una manera tan patente la vinculación existente entre el incremento de nuestra "inseguridad externa" y la presencia de los llamados regímenes de "seguridad nacional" en muchos países de América Latina. Desde la perspectiva que da el tiempo, hoy podemos apreciar con claridad que esos regímenes han terminado por erosionar las últimas bases de nuestra estabilidad y autonomía, de tal manera que hoy resulta evidente para amplios sectores que antes no lo veían el hecho de que la reconquista de esos valores pasa por el reestablecimiento de la democracia en América Latina. 
Estas breves consideraciones encierran todo un programa de reflexión y de acción que debería atraer la atención de los intelectuales y los hombres políticos de América Latina. En último término, esta problemática gira en torno a la acentuación de la vulnerabilidad externa de un grupo de países que debe enfrentar un contexto internacional caracterizado por violentas turbulencias con regimenes políticos no consensuales y no autonomistas, y apunta a la imperiosa necesidad de avanzar hacia el establecimiento de un sistema de seguridad regional latinoamericano basado en el fortalecimiento de la democracia en lo interno y en la búsqueda de un margen razonable de autonomía en el plano de las relaciones internacionales. A continuación se formulan algunas sugerencias referentes a los antecedentes, el contenido y los resultados que podria tener el análisis de esta problemática.

\section{Algunas Lecciones DE LA GUERRA}

El conflicto del Atlántico Sur no sólo habrá de traer graves consecuencias para los países directamente involucrados en la guerra, sino para toda América Latina, y en un plano aún más amplio ha puesto a prueba muchas de las estructuras y principios en que crefamos asentada la comunidad internacional contemporánea.

Los dirigentes políticos que tomaron las decisiones que de uno $\mathrm{u}$ otro lado desencadenaron el conflicto, no pudieron anticipar la inevitabilidad del estallido de la guerra, ni las proporciones que ésta habría de adquirir, ni las gravosas consecuencias que tendrá el conflicto tanto en lo internacional como en lo interno.

En este infortunado caso, los intelectuales tienen la triste oportunidad de poder apreciar, como nunca fue posible hacerlo en el curso de esta generación, las consecuencias que pueden derivarse de la falta de un análisis serio de las relaciones internacionales de nuestros países, así como la necesidad de realizar al menos ahora dicho análisis, a fin de suministrar elementos de juicio que permitan encarar con mayor racionalidad los resultados del conflicto.

La guerra ha dejado tras sí muchas lecciones:

- ha puesto desoladoramente en evidencia la ausencia de un "orden mundial" conducente al mantenimiento de la paz y a la eliminación del uso de la fuerza, y de un liderazgo capaz de mantener ese orden, a partir de valores sustantivos capaces de inspirar en forma estable y racional la conducta de las naciones.

- ha confundido momentáneamente los alineamientos establecidos hasta ahora dentro del marco del conflicto Este-Oeste, precisamente en momentos en que ese conflicto cobraba nuevamente especial virulencia, siendo utilizado para ejercer renovadas presiones encaminadas a estrechar filas dentro de cada bloque. 
- ha puesto en evidencia que, debido a la increíble estrechez de miras de los dirigentes mundiales, detrás del llamado diálogo Norte-Sur subsistía una abrumadora relación de dependencia, que las grandes potencias parecerían estar dispuestas a mantener a cualquier precio.

- ha quebrantado las bases en que hasta ahora se sustentó el Sistema Interamericano.

- ha puesto de manifiesto la fuerza y la debilidad que actualmente presenta la solidaridad latinoamericana, así como también la importancia de que los países de la región mantengan una poLítica auténticamente latinoamericanista, que les confiera un crédito a partir del cual puedan girar contra la región en mosoentos de crisis.

- ha subrayado de manera dramática la interrelación existente entre los aspectos internos y externos de la política exterior.

- ha permitido apreciar las pavorosas consecuencias económicas y políticas derivadas de la acción militar y de la intervención externa, planteando la necesidad de establecer un Sistema de Seguridad Regional Latinoamericano.

De estas lecciones se desprende toda una Innea de análisis centrada en torno a la necesidad de maximizar la seguridad externa y la autonomía del desarrollo de América Latina.

\section{El aumento de la insegurdida externa de Amériga latina}

Es un hecho bien establecido que la incertidumbre ha pasado a constituir uno de los rasgos centrales del escenario internacional contemporáneo. Sin embargo, no hemos analizado con la misma profundidad la peligrosa tendencia hacia el aumento de la inseguridad externa de América Latina, generada por factores internos $y$ externos. Entre ellos, a continuación se destacan tres órdenes de factores: las causas de la creciente vulnerabilidad económica, política y estratégica de América Latina; la erosión de sus principales marcos de acción internacional, y el impacto de los llamados regimenes de "seguridad nacional" sobre el incremento de la inseguridad de la región.

La crisis de las economías desarrolladas ha golpeado con fuerza a los países latinoamericanos, magnificando los problemas que estructuralmente han obstruido su proceso de desarrollo. Este impacto ha sido particularmente intenso e inmediato debido a que la economía internacional se ha vuelto más interdependiente, esto es, contiene mecanismos que actúan como poderosas poleas de transmisión de los fenómenos generados en los centros dinámicos hacia el resto del sistema. Entre esos mecanismos de transmisión se cuen$\tan$ la recesión que afecta a los países industrializados y la consi- 
guiente reducción de sus importaciones; el recrudecimiento del proteccionismo, por medio del cual aquellos países tratan de defenderse frente a estas tendencias recesivas, limitando más las exportaciones de los países de la periferia; la inflación registrada en los países centrales, que se propaga a la periferia a través del aumento de los precios de los bienes de capital y de las manufacturas, y cuyo efecto es reforzado por las elevadas tasas de interés prevalecientes; el aumento de los precios del petróleo, cuyo consumo los países en desarrollo no están en condiciones de comprimir sin amagar sus tasas de crecimiento económico; $y$, en fin, la transferencia hacia estos últimos países de estilos de desarrollo acuñados en los grandes centros industriales, que distorsionan sus procesos de desarrollo, sujetándolos a rigideces indebidas, y acentúan su vulnerabilidad externa.

En el plano político cabe llamar la atención, ante todo, hacia la crisis de hegemonía del mundo desarrollado y la ausencia de elementos que puedan fundamentar un nuevo "orden mundial" de carácter estable y más dinámico. Es dable también observar el avance del proceso de transnacionalización, con la consiguiente proliferación de juegos y de actores en gran parte independientes de los gobiernos, que persiguen una gran variedad de propósitos, con consecuencias frecuentemente desestabilizadoras y siempre complejas. Finalmente, es notoria la ausencia de nuevas reglas para el manejo de las relaciones entre los países desarrollados y el resto de la comunidal mundial, particularmente con los países en desarrollo.

En el plano estratégico, el efecto disuasivo causado por la acumulación de armamentos nucleares con respecto a la posibilidad de que estallen conflictos entre las grandes potencias, la necesidad de dirimir los conflictos potenciales mediante el uso de recursos convencionales, la consiguiente fragmentación del teatro de las operaciones, y el deseo de evitar la participación de las grandes potencias en ellos y de actuar a través de los llamados proxies, introducen en la palestra mundial a un creciente número de países y regiones en desarrollo, y acentúan su vulnerabilidad estratégica externa.

Todos estos factores de incertidumbre y desconcierto se reflejan en los principales marcos dentro de los cuales los países latinoamericanos han conducido tradicionalmente sus relaciones internacionales. Los acontecimientos que recientemente han afectado a nuestra región obligan a revisar las expectativas relacionadas con el diálogo Norte-Sur, teniendo en cuenta la reacción adversa de un número importante de países industrializados frente a los países latinoamericanos involucrados en ellos. Cuestionan, asimismo, los fundamentos sobre los cuales se construyó y ha funcionado hasta ahora el Sistema Interamericano. Finalmente, si bien ponen de re- 
lieve la importancia de la solidaridad latinoamericana, revelan al mismo tiempo su precariedad, planteando el desafío de avanzar más allá de motivaciones oportunistas y de resultados retóricos para cimentarlas sobre bases sólidas.

Por último, el conflicto del Atlántico Sur ha mostrado con impresionante claridad la estrecha correlación que existe entre el predominio de regímenes de "seguridad nacional" en una buena parte de América Latina y la grave erosión que ha experimentado su seguridad externa. Estos regímenes no sólo han violado los derechos humanos en cuya observancia se basa el respeto a la comunidad, han suprimido toda forma de participación política, se han identificado con los intereses más inconfesables, han hecho recaer el costo de la defensa de esos intereses sobre los más pobres, han dañado casi irreparablemente la unidad nacional y han detenido el desarrollo económico de sus países, sino que han desnacionalizado sus economias, las han abierto en forma indiscriminada frente a un contexto externo turbulento e incierto y han perdido todo sentido de ubicación en la comunidad internacional, cultivando un temerario aislamiento, alejándose de sus amigos naturales y ensayando aproximaciones y alianzas insensatas, cuando no siniestras. En particular, han entregado el manejo de sus relaciones externas a nuevos gobernantes, acompañados por economistas y banqueros desprovistos de sentido público, carentes de una visión equilibrada y amplia del sistema internacional contemporáneo y poseedores de vinculaciones demasiado evidentes con intereses externos de carácter privado, sustancialmente incompatibles con el desarrollo nacional de sus países. El margen de autonomía de estos últimos, cuya defensa debería excitar la imaginación de los dirigentes latinoamericanos dentro de un mundo crecientemente transnacionalizado, se ha visto recortada hasta álcanzar los límites más estrechos que. conoció en los últimos decenios. Mientras las bases internas de los regímenes políticos latinoamericanos no se transformen, éstos no podrán alcanzar, individual ni colectivamente, un grado aceptable de estabilidad, seguridad y autonomía.

Del mismo modo que la guerra de las Malvinas nos recordaba el trágico anacronismo de la carga de la caballería ligera en la guerra de Crimea, así el análisis de esos personajes y de sus más cercanos asesores revela una combinación altamente peligrosa de obsolescencia y estrechez de miras. Haciendo defender el porvenir de sus países casi exclusivamente de su participación en la carrera armamentista, de su preparación para la guerra y de su acceso a posiciones estratégicas, así como del logro de buenos indicadores económicos formales, parecen haber perdido de vista por completo todos los valores, aspiraciones y realidades en que se basa el desarrollo y el relacionamiento externo de nuestras sociedades. Sumidos 
en un impresionante aislamiento, no consideran ninguna de las cuestiones reales que concitarán la atención de la sociedad civil y los gobiernos, una vez reimplantada la democracia $-\mathrm{y}$ ello porque, en medio de la hábil retirada que han emprendido o están ensayando los militares en el Perú o el Brasil y del inminente derrumbe de los regímenes armados en el Cono Sur del continente, todavían piensan en términos de ajustes internos entre distintos segmentos de las fuerzas armadas y son incapaces de percibir las fuerzas que presionan por un retorno a la libertad y a la participación social.

\section{NEGESIDAD DE UN SISTEMA LATINOAMERICANO DE SEGURIDAD NACIONAL}

La incertidumbre, que ha pasado a caracterizar el sistema internacional contemporáneo, y el impacto que la creciente transmisión internacional de las perturbaciones políticas y económicas mundiales ejerce sobre los países latinoamericanos, destacan la necesidad de avanzar hacia el establecimiento de un mecanismo de seguridad colectivo en América Latina.

La experiencia en que se inspira esta sugerencia radica en el mecanismo de consulta que ha ido perfilandose entre los siete países mayores con economía de mercado, cuya última reunión se efectuó en Versalles. Mientras los países latinoamericanos no dispongan de una capacidad de consulta y coordinación tan eficaz como la que poseen los países industrializados, su poder de negociación carecerá de una base adecuada. Esa incapacidad afecta, por una parte, la autonomía del desarrollo de cada uno de ellos y, por la otra, la eficacia de todas las organizaciones existentes para promover la cooperación latinoamericana.

En efecto, a diferencia de lo que ocurre en otras regiones del mundo, la experiencia latinoamericana en esta materia es extremadamente escasa (reduciéndose a un convenio aprobado por la OEA en 1977, que no fue ratificado, antecedido por un proyecto presentado por el Brasil al Ecosoc cuatro años antes). Además, las pocas iniciativas encaminadas a adoptar un sistema de seguridad colectiva incluyen en forma destacada a los Estados Unidos en el doble papel de principal garante y agresor potencial de tal sistema, contradicción que lo habría debilitado fundamentalmente, como se ha puesto de manifiesto en forma dramática con el reciente conflicto de las Malvinas.

Dicho conflicto subraya la necesidad de avanzar hacia un mecanismo de esta especie. El nuevo mecanismo debería consistir fundamentalmente en un órgano de consulta muy flexible pero instituido al más alto nivel político posible. Su flexibilidad debería 
expresarse tanto en su poder de convocatoria, como en las causales susceptibles de ser invocadas para promover una acción colectiva y en las medidas que podrían ser aplicadas, evitando reglamentaciones detalladas. Su alto nivel político impediría que sus funciones fuesen delegadas en una secretaría de carácter burocrático. En cambio, para el estudio y ejecución de sus resoluciones, el órgano de consulta debería utilizar intensamente tadas las organizaciones regionales existentes, dentro de sus respectivas esferas de competencia. Desde el punto de vista de estas últimas, su creación equivaldría a acoplar un poderoso motor político a la maquinaria regional que actualmente existe.

Estos propósitos no se lograrán mediante la constitución de una especie de "sala latinoamericana" dentro de la OEA, como por falta de información acerca del contexto internacional de América Latina se sugirió recientemente en un cónclave de inspiración nacionalista, sino a través de la creación de un órgano de consulta exclusivamente latinoamericano.

Tampoco se lograrán mediante reuniones de ministros latinoamericanos de defensa, Ia creación de una Escuela Militar Latinoamericana o el incremento de los ejercicios militares en que participan las naciones del Hemisferio Occidental, como lo planteó el General Walter Somner, vocero del Departamento de Estado, en un seminario realizado en Santiago de Chile en el mes de julio de este año, como por lo demás lo ha demostrado ampliamente la experiencia reciente, sino a través del fortalecimiento de las instituciones democráticas en nuestros países, Ia subordinación a ellas de las fuerzas armadas y el establecimiento de un organismo consultivo regional de carácter político.

Es ésta al parecer la tesis que inspira las consultas que ha efectuado ante otros gobiernos en nombre de Argentina el embajador de ese país ante la OEA, Raúl Quijano, en torno a la posibilidad de concebir un organismo "estrictamente latinoamericano", que complemente a la OEA y el TXAR, y atienda nuestros propios problemas. Esta es también la tesis implícita en las declaraciones del presidente de la Comisión de Relaciones Exteriores de Venezuela, diputađo José Rodríguez Iturbe, en el sentido de que su gobierno estaría estudiando un proyecto para la creación de un Consejo de Ministros de Relaciones Exteriores de los países latinoamericanos, que responda a la apreciación de que "más que nuevas estructuras y burocracias internacionales, nuestros países requieren de mecanismos sencillos y rápidos para la realización de consultas y la definición conjunta de posiciones en el ámbito internacional". En la Declaración Conjunta de las Cancillerías de Chile y Perú, suscrita en Santiago el 20 de agosto, se destaca asimismo la importancia de "establecer mecanismos eficaces de consulta" entre los países latino- 
americanos. Por último, ese podría ser también.. el propósito que está detrás del llamamiento formulado reiteradamente por el nuevo presidente de Colombia, en el sentido de propiciar una reunión cimera entre los mandatarios latinoamericanos, por más que hasta ahora estas iniciativas adolezcan de una evidente vaguedad en lo que se refiere a sus motivaciones $y$, sobre todo, a sus posibles metas:

La tendencia señalada más airiba hacia un mundo multipolar - pluralista, al debilitar la "relación especial" que América Latina procuró mantener durante largos años con los Estasos Unidos en nombre de una pretendida "armonía natural de intereses", cuya inexistencia se ha puesto de manifiesto tantas veces y al promover la diversificación de sus relaciones externas, avalan la necesidad de un mecanismo de esta especie. El desarrollo que - si bien registrando grandes diferencias - a lo largo de los últimos decenios han venido experimentando nuestros países, varios de los cuales han alcanzado ya una etapa de desarrollo intermedio que requiere, como contrapartida, de un grado mayor de autonomía externa, es otra razón que justifica este planteo. Desafortunada y contradictoriamente, hasta ahora el crecimiento de sus pafses fue acompañado de fuertes tendencias centrífugas, hasta el punto de que probablemente en lo que va corrido de este siglo nunca nuestros países habian estado divididos por percepciones, ideologías y actitudes más profundas. Hay felizmente también algunos casos, como el retorno del Brasil a una amplia apertura hacia América Latina, que parecieran mostrar el lógico corolario externo de un prolongado proceso de maduración y desarrollo. Pero no creemos casual que en ese caso el retorno a América Latina pase por el retorno a la democracia.

El establecimiento de un mecanismo de consulta como el que se sugiere, obviamente sería facilitado por el retorno a sistemas democráticos o consensuales de gobierno. Si una lección al menos hubiéramos de extraer de esta experiencia, consistiría en la incompatibilidad que existe entre los regímenes de "seguridad nacional" y Ia seguridad externa de nuestros países, y en la necesidad de que ésta se asiente en el retorno democrático.

Los regímenes autoritarios inspirados en la doctrina de la seguridad nacional han dividido las sociedades respectivas y erosionado sut unidad interna, sin la cual no puede haber seguridad exterior, hasta un extremo que nuestros países no habian conocido a Io Iargo de su vida independiente. AI promover una exagerada apertura de sus economías, comprometer la base industrial de sus países y acentuar su dependencia frente al crédito externo y a una creciente gama de productos importados, dentro de un contexto internacional extremadamente incierto, han agravado peligrosamente la vulnerabilidad internacional de nuestros países.

Requisito esencial de esa apertura externa ha sido siempre el 
mantenimiento de un bajo perfil en materia de política internacional, con la consiguiente ausencia de los países respectivos de los foros y temas en que están en juego sus más tradicionales intereses. Ello conduce indefectiblemente a groseros errores de apreciación acerca de las condiciones prevalecientes en el contexto externo y del probable comportamiento de los demás actores. La visión de la Argentina en vísperas del conflicto de las Malvinas acerca de su pertenencia al mundo occidental y su alienación respecto al Tercer Mundo, constituye un claro ejemplo de lo dicho. La historia demuestra que sólo los sistemas democráticos, a pesar de sus posibles debilidades desde un punto de vista operativo, son capaces de tener una visión internacional más amplia y objetiva. Sólo a partir de ellos podrá tener perspectivas de éxito, en definitiva, cualquier iniciativa encaminada a establecer un sistema de seguridad regional latinoamericano a un nivel político adecuado para garantizar la efectividad de tal sistema. 